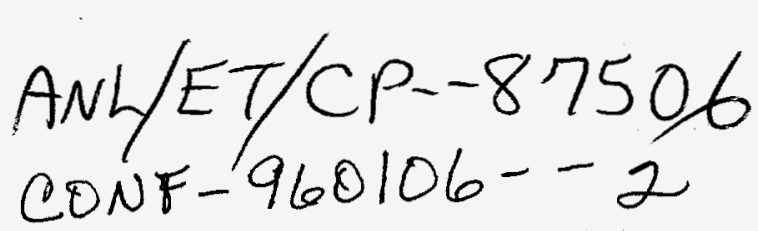

\title{
INFLUENCE OF FIBER LAY-UP SEQUENCE ON MECHANICAL PROPERTIES OF $\mathrm{SIC}(\mathrm{f}) / \mathrm{SIC}$ COMPOSITES*
}

\author{
Dileep Singh, Jitendra P. Singh, and Manish Sutaria \\ Energy Technology Division \\ Argonne National Laboratory \\ Argonne, Illinois 60439
}

January 1996

The submitted manuscript has been authored by a contractor of the U.S. Government under contract No. W-31-109-ENG-38. Accordingly, the U.S. Government retains a nonexclusive, royalty-free license to publish or reproduce the published form of this contribution, ar allow others to do so, for U.S.

Government purposes.

\section{IE FER 281996 OSTI} IVED

\section{DISCLAIMER}

\begin{abstract}
This report was prepared as an account of work sponsored by an agency of the United States Government. Neither the United States Government nor any agency thereof, nor any of their employees, makes any warranty, express or implied, or assumes any legal liability or responsibility for the accuracy, completeness, or usefulness of any information, apparatus, product, or process disclosed, or represents that its use would not infringe privately owned rights. Reference herein to any specific commercial product, process, or service by trade name, trademark, manufacturer, or otherwise does not necessarily constitute or imply its endorsement, recommendation, or favoring by the United States Government or any agency thereof. The views and opinions of authors expressed herein do not necessarily state or reflect those of the United States Government or any agency thereof.
\end{abstract}

For publication in Proceedings of 20th Annual Conference on Composites and Advanced Ceramics, American Ceramic Society, Cocoa Beach, FL, January 7-11, 1996.

*Work supported by U.S. Department of Energy, Advanced Research and Technology Development, Fossil Energy Material Program, under Contract W-31-109-Eng-38. 


\section{DISClaAMER}

Portions of this document may be illegible in electronic image products. Images are produced from the best available original document. 


\title{
INFLUENCE OF FIBER LAY-UP SEQUENCE ON MECHANICAL
} PROPERTIES OF SiC(f)/SiC COMPOSITES

Dileep Singh, Jitendra P. Singh, and Manish Sutaria

Energy Technology Division, Argonne National Laboratory

Argonne, Illinois 60439

\begin{abstract}
Mechanical properties of Nicalon-fiber-reinforced silicon carbide matrix composites with two different fiber lay-up sequences $\left(0^{\circ} / 40^{\circ} / 60^{\circ}\right.$ and $\left.0^{\circ} / 45^{\circ}\right)$ were evaluated at various temperatures ranging from ambient to $1300^{\circ} \mathrm{C}$. Composites with $0 \% 40^{\circ} / 60^{\circ}$ fiber lay-up sequence showed a higher average first matrix cracking stress than that of $0^{\circ} / 45^{\circ}$ composites. The measured room-temperature ultimate strength of the $0^{\circ} / 40^{\circ} / 60^{\circ}$ composites was $300 \mathrm{MPa}$, compared to $180 \mathrm{MPa}$ for the $0^{\circ} / 45^{\circ}$ composites. These measured ultimate strengths were correlated to the predictions made with an analytical model and to in-situ fiber strength characteristics. The large difference in room-temperature ultimate strengths between the two sets of composites is attributed to the relative contributions of the off-axis fibers to the load-bearing capacity of each composite. Up to $1200^{\circ} \mathrm{C}$, ultimate strength and work-of-fracture in each set of composites increased, but then declined above $1300^{\circ} \mathrm{C}$. The decreases were correlated to in-situ Nicalon fiber strength and fiber/matrix interface degradation.
\end{abstract}

\section{INTRODUCTION}

Continuous fiber-reinforced ceramic matrix composites (CFCCs) are being pursued as materials for structural applications in various industries, including automotive, aerospace, and utilities, chiefly because of the combination of high strength and toughness provided by these composites at both room and elevated temperatures $[1,2]$. It has now become clear that the mechanical response of CFCCs, for a fixed fiber content, is largely controlled by intrinsic composite parameters, including strengths of the reinforcing fibers and matrix [3,4], fiber/matrix interface characteristics [5,6], and internal residual stresses [7]. However, in recent years, demanding material-performance needs such as multiaxial stress states have necessitated development of CFCCs with increasingly complex designs. To date, only limited experimental studies have been conducted to establish correlations between material design parameters such as fiber orientation and composite properties. Therefore, to develop CFCCs with improved mechanical reliablity for 
practical structural applications, we must evaluate the mechanical performance of the CFCCs and correlate it to the fiber orientation in the composites.

In the present study, chemical vapor infiltrated $\mathrm{SiC}$-fiber-reinforced $\mathrm{SiC}$ matrix composites were used in evaluating mechanical properties with various fiber lay-up sequences. Rectangular bars of composites were tested in flexural mode at room and elevated temperatures. Variations in mechanical properties such as first matrix cracking stress, ultimate strength, and work-of-fracture were evaluated as a function of test temperature. Strength of in-situ fibers in composites at room and elevated temperatures were measured by fractographic techniques. Correlations were made between observed composite mechanical properties and fiber lay-up sequences to establish the effect of fiber orientation on mechanical properties at room and elevated temperatures.

\section{EXPERIMENTAL PROCEDURE}

\section{Material}

Nicalon ( $\mathrm{SiC}$ )-fiber-reinforced $\mathrm{SiC}$ matrix composites, fabricated by Ceramic Composites, Inc. (Millersville, MD), were chosen for this study because of their potential for high-temperature structural use in components in advanced heat engines and hot-gas filters. These composites were fabricated by densifying multiple layers of 2-D plain weave Nicalon mats with a chemical vapor infiltration process. Composites with two different lay-up sequences $\left(0^{\circ} / 40^{\circ} / 60^{\circ}\right.$ and $\left.0^{\circ} / 45^{\circ}\right)$ were tested. The fibers were coated with carbon to a thickness of $0.4 \mu \mathrm{m}$ in both sets of composites. Fiber content in the final composite was $\approx 40 \mathrm{vol} . \%$. The composites were fabricated into billets from which rectangular bar specimens were cut for evaluation of mechanical properties. Densities of composites with fiber layup sequences of $0^{\circ} / 40^{\circ} / 60^{\circ}$ and $0^{\circ} / 45^{\circ}$, measured by the fluid displacement method, were 2.25 and $2.35 \mathrm{~g} / \mathrm{cm}^{3}$, respectively.

\section{Mechanical Testing}

Flexure testing in a four-point-bend mode were used to evaluate mechanical properties of the composites at room and elevated temperatures. This method was chosen because of its relatively low cost and ease of use. For room-temperature tests, flexural bars $(2.9 \times 4.2 \times 25.4 \mathrm{~mm})$ were tested with loading and support spans of 9.5 and $19.0 \mathrm{~mm}$, respectively. All tests were conducted at a crosshead speed of $1.27 \mathrm{~mm} / \mathrm{min}$ at ambient conditions on a universal testing machine.

High-temperature flexure tests were conducted at three different temperatures: 1000,1200 , and $1300^{\circ} \mathrm{C}$. The composite bars $(2.9 \times 4.2 \times 28.0 \mathrm{~mm})$ were similar to those tested at room temperature except for an additional $\mathrm{SiC}$ surface coating 
$(\approx 100 \mu \mathrm{m}$ thick) to prevent oxidizing the exposed carbon coating on the fiber surfaces. SiC fixtures with loading and support spans of 12.7 and $25.4 \mathrm{~mm}$, respectively, were used, and crosshead speed was $1 \mathrm{~mm} / \mathrm{min}$. All specimens were loaded perpendicular to the mat layers. At each test conditions at least three specimens were tested. Fractured composite specimens were examined on a scanning electron microscope (SEM) to locate and identify critical flaws in the fibers. In addition, pullout length of fractured fibers was measured to establish fiber/matrix interfacial strength characteristics. The procedure for measuring fiber pullout length was somewhat similar to that employed by Thouless et al. [4].

The first matrix cracking stress, or onset of permanent damage of the composites, was determined from the load at which first deviation from the linear variation in the load-vs.-displacement plots was observed. Nominal ultimate stress was determined from the peak load value. Composite work-of-fracture (WOF) was estimated from the total area under the load-specimen displacement plots normalized on the basis of unit cross-sectional area of the fractured composites. True specimen displacement was obtained by subtracting system displacement from total displacement (system displacement was determined by measuring system compliance with a stiff alumina piece).

\section{ANALYTICAL BACKGROUND}

Mechanical response of continuous fiber-reinforced ceramic matrix composites with increasing stress levels is dependent on in-situ fiber strength and its distribution. Based on the weakest-link-principle, i.e., failure occurs at the most severe flaw, strength distribution of fibers can be represented by the Weibull distribution function as follows:

$$
\mathrm{F}(\sigma)=1-\exp \left[-\frac{\mathrm{L}}{\mathrm{L}_{\mathrm{o}}}\left(\frac{\sigma}{\sigma_{\mathrm{o}}}\right)^{\mathrm{m}}\right],
$$

where $F(\sigma)$ is the cumulative failure probability at an applied stress $\sigma, \sigma_{0}$ is the scale parameter signifying a characteristic fiber strength at a fiber gauge length, $\mathrm{L}_{\mathrm{O}}$, and $\mathrm{m}$ is referred to as the Weibull modulus that characterizes flaw distribution in the material. Thus, by using the Weibull distribution function as given by Eq. 1, it is possible to estimate Weibull scale parameter at some standard gauge length, $\mathrm{L}$, using the following expression: 


$$
\sigma=\sigma_{\circ}\left(\frac{L_{o}}{L}\right)^{\frac{1}{m}}
$$

The in-situ fiber strength distribution parameters, $\sigma_{\mathrm{c}}$ and $\mathrm{m}$, can be evaluated by measuring mirror sizes on fractured fibers. Typical flaw morphology and associated fracture features such as mirrors (smooth region) and hackles (regions of multiple fracture planes) on a Nicalon fiber in a composite tested at room temperature are shown in Fig. 1. For brittle materials such as glasses and ceramics, it is possible to correlate sizes of fracture features to fracture stress with empirical relationships. For example, fracture stress, $\sigma_{f}$, of the fibers can be obtained from mirror-size measurements with the following relationship [8]:

$$
\sigma_{\mathrm{f}}=\frac{3.5 \mathrm{~K}_{\mathrm{f}}}{\sqrt{\mathrm{r}_{\mathrm{m}}}}
$$

where $r_{m}$ is the mirror radius and $K_{f}$ is the fracture toughness of the fiber. This semiempirical relationship is applicable for mirror sizes much smaller than the fiber diameter.

Based on the fiber fragmentation theory [7], the resulting value of scale parameter, $\sigma_{c}$, from fracture mirror evaluations is at a gauge length, $L_{c}$, that is controlled by fiber/matrix interfacial shear strength and fiber strength. An average value for the gauge length for in-situ fractured fibers can be written as

$$
\mathrm{L}_{\mathrm{c}}=\mathrm{r} \frac{\sigma_{\mathrm{c}}}{\tau}
$$

where $\mathrm{r}$ is the fiber radius and $\tau$ is the fiber/matrix interfacial shear strength.

The fiber/matrix interfacial shear strength can be determined from average fiber pullout length measurement, $h$, as $[4,7]$

$$
\tau=\frac{\lambda(\mathrm{m}) \mathrm{r} \sigma_{\mathrm{c}}}{4 \mathrm{~h}}
$$

where $\lambda(\mathrm{m})$ is a nondimensional function and is dependent on fiber fracture statistics. 


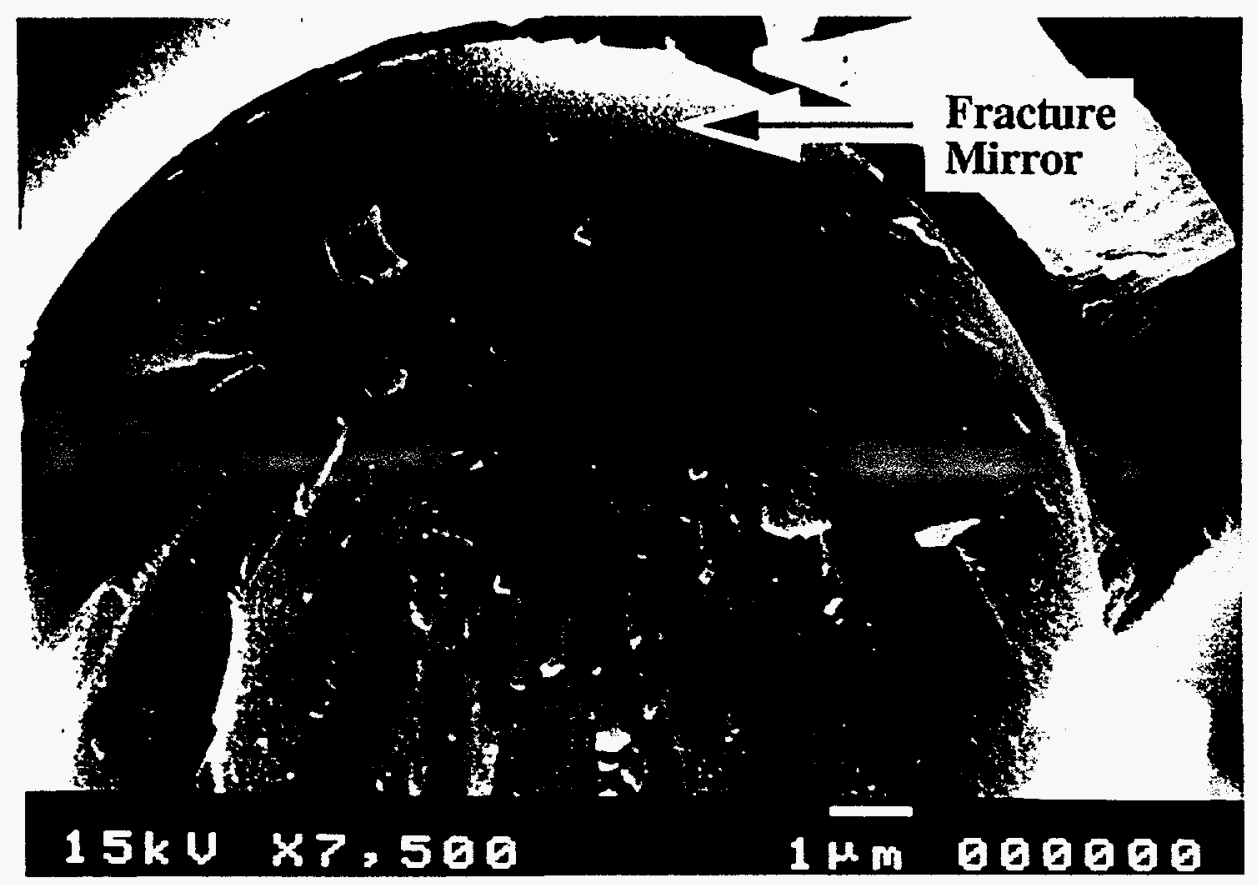

Fig. 1. Fracture Surface Morphology of SiC (Nicalon) Fiber.

In-situ fiber strength distribution parameters $\left(\sigma_{\mathrm{c}}\right.$ and $\mathrm{m}$ ) can be correlated to the ultimate strength, $\sigma_{\mathrm{UTS}}$, of the composite as follows [7]:

$$
\sigma_{\mathrm{UTS}}=\mathrm{f}_{1} \sigma_{c}\left[\frac{2}{\mathrm{~m}+2}\right]^{1 / \mathrm{m}+1}\left[\frac{\mathrm{m}+1}{\mathrm{~m}+2}\right],
$$

where $f_{l}$ is the fiber volume fraction parallel to the loading direction.

\section{RESULTS AND DISCUSSION}

Figure 2 shows typical load-displacement behavior obtained from flexure tests conducted on $\mathrm{SiC}_{(\mathrm{f})} / \mathrm{SiC}$ composites with $0 \% / 40^{\circ} / 60^{\circ}$ fiber lay-up sequence at both room and elevated temperatures. Similar variations in load displacement were observed for the $0^{\circ} / 45^{\circ}$ composites. Gradual failure was observed in all tests. However, the area under the curve increased somewhat in tests at elevated temperatures. It is recognized here that because of the generation of matrix crack(s) 
and the shift in the neutral axis, use of the simple beam theory to assess ultimate stresses gives a semiquantitative estimate of ultimate strength. However, the purpose of estimating these values is to compare the relative load-bearing properties of the composites under specific fiber orientations and test conditions.

The room-temperature first matrix cracking stress for the composites with fiber layup sequences $0^{\circ} / 40^{\circ} / 60^{\circ}$ and $0^{\circ} / 45^{\circ}$ were $115 \pm 28$ and $86 \pm 26 \mathrm{MPa}$, respectively. Variations in ultimate strength of the two composites are shown in Fig. 3. At room temperature, ultimate strength of $0 \% / 40^{\circ} / 60^{\circ}$ composites $(\approx 300 \mathrm{MPa})$ was significantly higher that of $0^{\circ} / 45^{\circ}$ composites $(\approx 180 \mathrm{MPa})$. At $1000^{\circ} \mathrm{C}$, the strength of $0 \% 140^{\circ} / 60^{\circ}$ composites was similar to its room-temperature value. No $0 \% 45$ specimens were available for tests at $1000^{\circ} \mathrm{C}$. Beyond $1000^{\circ} \mathrm{C}$, the ultimate strengths of both sets of composites increased dramatically over their roomtemperature values, probably because of matrix-softening effects at elevated temperatures. Such behavior is well documented in monolithic ceramics and CFCCs [9]. In general, at elevated temperatures, the $0^{\circ} / 40^{\circ} / 60^{\circ}$ composites had higher strengths than those of the $0^{\circ} / 45^{\circ}$ composites. However, at $1300^{\circ} \mathrm{C}$, strengths of both sets of composites dropped to $\approx 270 \mathrm{MPa}$. This decrease in strength above $1200^{\circ} \mathrm{C}$ is believed to be due to the degradation in strength of the reinforcing fibers [10-12].

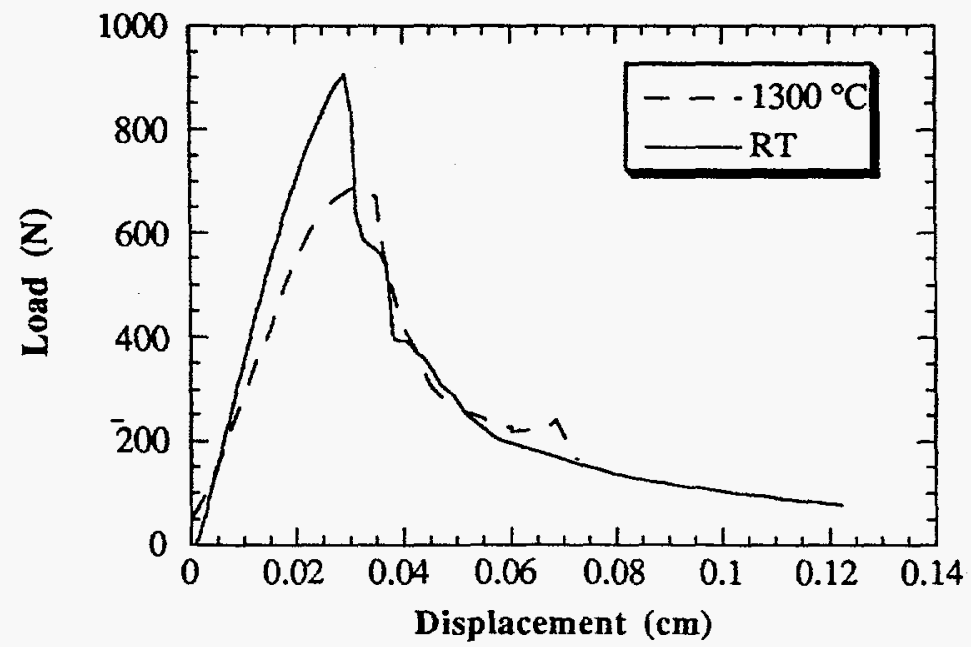

Fig. 2. Typical Load Displacement Observed for $0 \% 40^{\circ} / 60^{\circ}$ Composites Tested at Room Temperature and $1300^{\circ} \mathrm{C}$. 


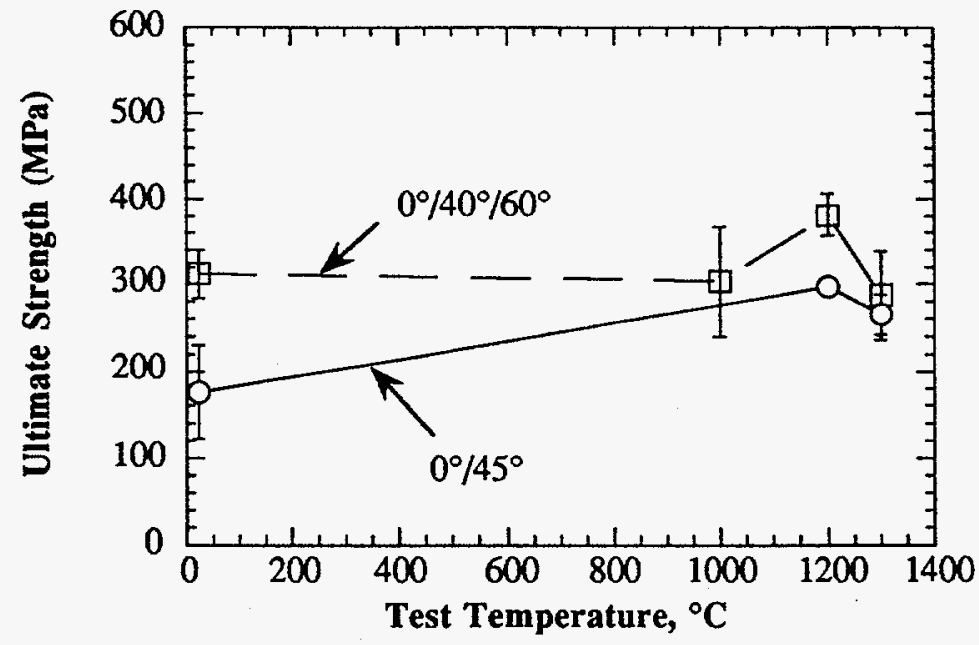

Fig. 3. Variation of Ultimate Strength with Test Temperature for $\mathrm{SiC}(\mathrm{f}) / \mathrm{SiC}$ Composites of Two Different Fiber Lay-up Sequences.

To establish the large difference in room-temperature strengths of $0 \% 40 \% 60^{\circ}$ and $0^{\circ} / 45^{\circ}$ composites, we measured their in-situ fiber strengths and correlated them to the composite strengths. In-situ fiber strength measurements by fractography were made on the two sets of composites samples fractured at room temperature. In most fibers, fractures originated at surface flaws, as shown in Fig. 1. Using mirror size measurements and a value of $1 \mathrm{MPa} \sqrt{\mathrm{m}}$ as the Nicalon fiber fracture toughness [4], we estimated fiber strengths from Eq. 3. These strength values were then used to construct linearized Weibull plots with Eq. 1.

Figure 4 shows the linearized Weibull plots of in-situ fibers in $0^{\circ} / 40^{\circ} / 60^{\circ}$ and $0^{\circ} / 45^{\circ}$ composites tested at room temperature. The scale parameter and Weibull modulus for the $0^{\circ} / 40^{\circ} / 60^{\circ}$ composites were 2.42 and $4.9 \mathrm{GPa}$, respectively, while the $0^{\circ} / 45^{\circ}$ composites had a scale parameter and Weibull modulus of 2.38 and $4.9 \mathrm{GPa}$, respectively. Associated average fiber pullout lengths were 160 and $200 \mu \mathrm{m}$ for $0 \% / 45^{\circ}$ and $0 \% 140^{\circ} / 60^{\circ}$ composites, respectively.

For comparison purposes, the scale parameters for the fractured fibers in $0^{\circ} / 40^{\circ} / 60^{\circ}$ and $0 \% 45^{\circ}$ composites tested at room temperature were evaluated at a standard gauge length of $1 \mathrm{~mm}$. This was done by first estimating the gauge length, $\mathrm{L}_{\mathrm{c}}$, for the fractured fibers in the composites tested with the two fiber lay-up sequences, based 


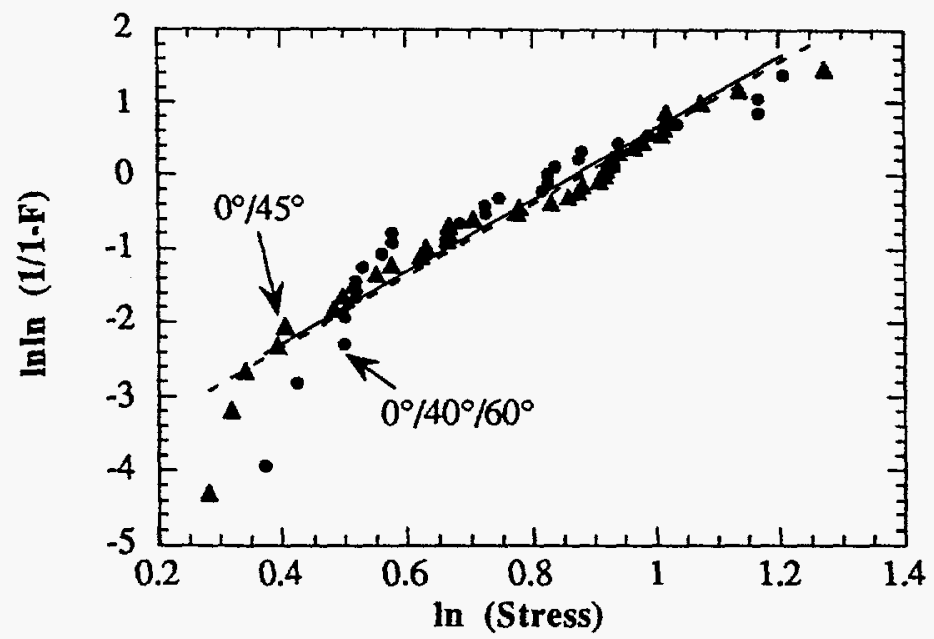

Fig. 4. Linearized Weibull Strength Distributions for InSitu Nicalon Fibers in Composites with Two Different Fiber Lay-Up Sequences.

on the average fiber pullout lengths and the scale parameters. Fiber radius was assumed to be $8 \mu \mathrm{m}$, and $\lambda$ was taken as 2.1 for fibers tested in both $0 \% 40^{\circ} / 60^{\circ}$ and $0 \% 45^{\circ}$ composites [7]. The corresponding values for the gauge lengths of fractured fibers were estimated as 381 and $305 \mu \mathrm{m}$ for the $0^{\circ} / 40^{\circ} / 60^{\circ}$ and $0^{\circ} / 45^{\circ}$ composites, respectively. Subsequently, these fiber gauge lengths were used in conjunction with Eq. 2 to estimate scale parameters for the in-situ fibers at a gauge length of 1 $\mathrm{mm}$. Thus, the scale parameters at a gauge length of $1 \mathrm{~mm}$ for in-situ fractured fibers in the $0 \% 40^{\circ} / 60^{\circ}$ and $0^{\circ} / 45^{\circ}$ composites tested at room temperature were 2 and $1.87 \mathrm{GPa}$, respectively. These values were then used to plot Weibull distribution curves (Fig. 5). Similarity in the Weibull strength distribution plots suggests that there are no differences in the fiber strength characteristics for the in-situ fibers in the two sets of composites.

Equation 6 was used to determine the ultimate strengths of the $0^{\circ} / 40^{\circ} / 60^{\circ}$ and $0^{\circ} / 45^{\circ}$ composites tested at room temperature. As a first approximation, the fraction of fibers along the loading direction (i.e., $0^{\circ}$ ) are accounted for in the calculations. Therefore, values of $f_{1}$ for the $0^{\circ} / 40^{\circ} / 60^{\circ}$ and $0^{\circ} / 45^{\circ}$ composites are 0.07 and 0.1 , respectively. Based on these values and the Weibull parameters, predicted ultimate strengths for the $0 \% 40^{\circ} / 60^{\circ}$ and $0^{\circ} / 45^{\circ}$ composites are 117 and $165 \mathrm{MPa}$. The 


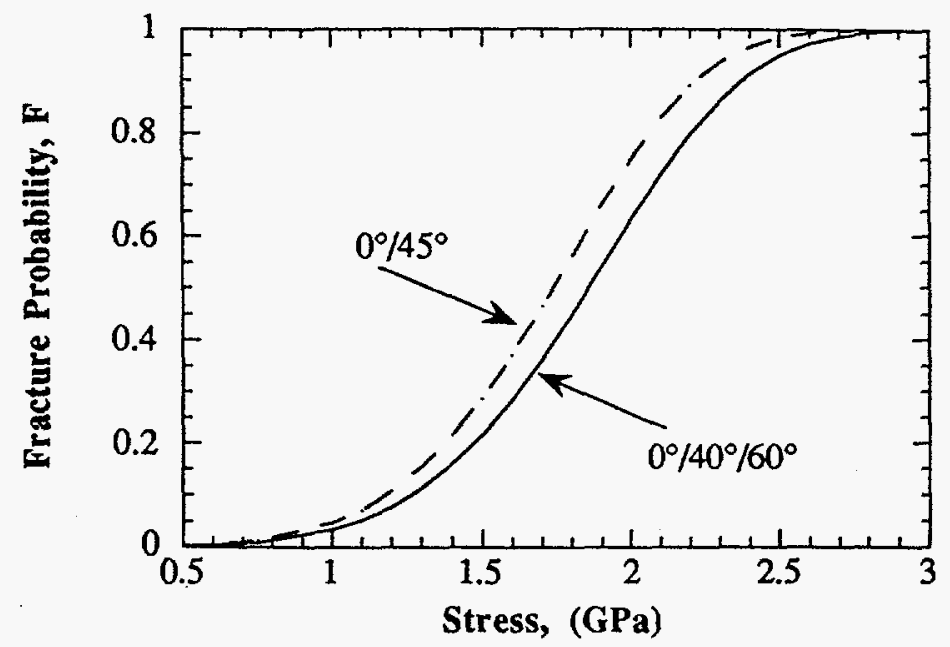

Fig. 5. Weibull Strength Distribution of In Situ Nicalon Fibers in $0^{\circ} / 40^{\circ} / 60^{\circ}$ and $0 \% 45^{\circ}$ Composites at a Gauge Length of $1 \mathrm{~mm}$.

predicted strength for the $0 \% 45^{\circ}$ composites agrees well with the observed roomtemperature strength of $\approx 180 \mathrm{MPa}$, while for the $0^{\circ} / 40^{\circ} / 60^{\circ}$ composites, there is a large discrepancy. It is possible that in the $0^{\circ} / 40^{\circ} / 60^{\circ}$ composites, fibers in the layups oriented at $40^{\circ}$ and $30^{\circ}$ (in $60^{\circ}$ oriented mats) may be contributing to the mechanical response of the composite. If the contribution of these fibers is included in the model, the predicted strength for the $0 \% 140^{\circ} / 60^{\circ}$ is $\approx 334 \mathrm{MPa}$; this is in accordance with the observed strength of $\approx 300 \mathrm{MPa}$. Thus, from this work it seems that fibers oriented off-axis by more than $45^{\circ}$ do not contribute significantly to the ultimate strength of the composites. However, if they are oriented $<40^{\circ}$ from the loading direction, they do have influence on the composite strength. Realistically, the contribution of the off-axis fibers on the composite strength is expected to change gradually with the off-axis angle and needs to be further quantified. In addition to the fiber fraction available to sustain the applied loads, there may also be a change in the failure mechanism as the fiber lay-up sequence changes in the composites.

Observed WOF variation with test temperature of both sets of composites was similar and is shown in Fig. 6. With increasing test temperature, WOF increased to a maximum at $1200^{\circ} \mathrm{C}$ because of matrix-softening effects, but drops rapidly above $1300^{\circ} \mathrm{C}$. This drop is related to physical changes in the in-situ Nicalon fibers in 


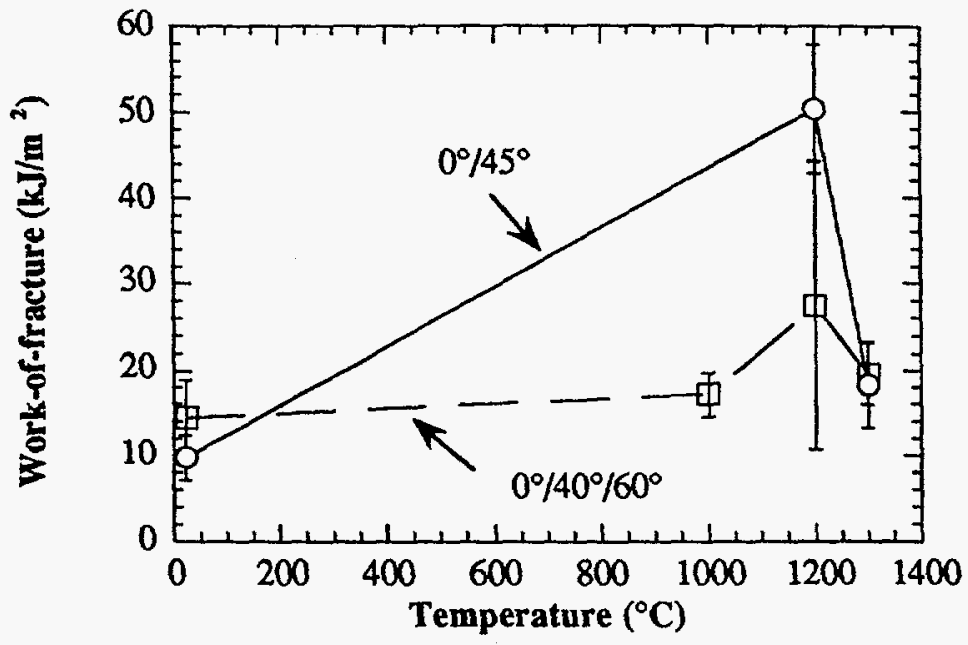

Fig. 6. Variation of Work-of-Fracture with Test Temperature for $\mathrm{SiC}(\mathrm{f}) / \mathrm{SiC}$ Composites with Two Different Fiber Lay-up Sequences.

composites tested at elevated temperatures; formation of silica at the fiber surface is a distinct possibility at elevated temperatures and can lead to degradation of fiber/matrix interfacial properties. This oxidation can minimize the effective fiber pullout during fracture of the composites, thus accounting for WOF values [13].

\section{CONCLUSIONS}

1. Room-temperature mechanical response (specifically, ultimate strength) of $\mathrm{SiC}(\mathrm{f}) / \mathrm{SiC}$ composites is dependent on fiber lay-up sequence.

2. Correlation of measured ultimate strength and prediction based on in-situ fiber strength characteristics, together with an analytical model for composites with $0^{\circ} / 40^{\circ} / 60^{\circ}$ and $0^{\circ} / 45^{\circ}$ fiber lay-up sequences, suggests that fibers off-axis by more than $40^{\circ}$ from the loading direction contribute only minimally to ultimate strengths of composites. 
3. At elevated temperatures, mechanical properties of both sets of composites increase due to matrix-softening effects. However, at $1300^{\circ} \mathrm{C}$, both ultimate strength and work-of-fracture degrade, probably because of degradation in the Nicalon fibers and to increased fiber/matrix interfacial shear strengths because of oxidation effects.

\section{ACKNOWLEDGMENTS}

This work has been supported by U.S. Department of Energy, Advanced Research and Technology Development, Fossil Energy Materials Program, under Contract W-31-109-Eng-38.

\section{REFERENCES}

1. A. G. Evans and D. B. Marshall, "The Mechanical Behavior of Ceramic Matrix Composites," Overview No. 85, Acta Metall., 37 [10] 2567-2583 (1989).

2. E. Y. Luh and A. G. Evans, "High-Temperature Mechanical Properties of a Ceramic Matrix Composite," J. Am. Ceram. Soc., 70 [7] 466-69 (1987).

3. T. Mah, M. G. Mendiratta, A. P. Katz, R. Ruh, and K. S. Mazdiyasni, "Room-Temperature Mechanical Behavior of Fiber-Reinforced CeramicMatrix Composites," J. Am. Ceram. Soc., 68 [1] C-27-C-30 (1985).

4. M. D. Thouless, O. Sbaizero, L. S. Sigl, and A. G. Evans, "Effect of Interface Mechanical Properties on Pullout in a SiC-Fiber-Reinforced Lithium Aluminate Silicate Glass Ceramic," J. Am. Ceram. Soc., 72 [4] 525-32 (1989).

5. H. C. Cao, E. Bishcoff, O. Sbaizero, M. Ruhle, A. G. Evans, D. B. Marshall, and J. J. Brennan, "Effect of Interfaces on the Properties of Fiber-Reinforced Ceramics," J. Am. Ceram. Soc., 73 [6] 1691-99 (1990).

6. R. N. Singh, "Fiber-Matrix Interfacial Characteristics in a FiberReinforced Ceramic-Matrix Composite," J. Am. Ceram. Soc., 72 [9] 1764-67-(1989).

7. W. A. Curtin, "Theory of Mechanical Properties of Ceramic-Matrix Composites," J. Am. Ceram. Soc., 74 [11] 2837-45 (1991).

8. R. W. Rice, Treatise on Materials Science and Technology, Vol. II, pp. 199, Academic Press, New York, 1978.

9. D. P. Stinton, R. A. Lowden, and R. H. Krabill, "Mechanical Property Characterization of Fiber-Reinforced SiC Matrix Composites," in Proc. 4th Annual Conf. on Fossil Energy Materials, Fossil Energy AR\&TD Materials Program, ORNL/FMP-90/1, 3-13 (1990).

10. D. Singh, J. P. Singh, and M. Wheeler, "Mechanical Behavior of $\mathrm{SiC}(\mathrm{f}) / \mathrm{SiC}$ Composites and Correlation to In-Situ Fiber Strength at Room 
and Elevated Temperatures," to appear in Journal of the American Ceramic Society.

11. T. J. Clark, R. M. Arons, and J. B. Stamatoff, "Thermal Degradation of Nicalon SiC Fibers," Ceram. Eng. Sci. Proc., 6 [7-8] 576-588 (1985).

12. D. J. Pysher, K. C. Goretta, R. S. Hodder, and R. E. Tressler, "Strengths of Ceramic Fibers at Elevated Temperatures," J. Am. Ceram. Soc., 72 [2] 284-88 (1989).

13. R. A. Lowden and D. P. Stinton, "Interface Modification in Nicalon/SiC Composites," Ceram. Eng. Sci. Proc., 9 [7-8] 705-722 (1988). 